\title{
Avascular Necrosis of the Femoral Head in HIV Infected Patients
}

Marcos Almeida Matos, Rafael Watt de Alencar and Simone Souza da Rocha Matos Medical School of Medicine and Public Health; Salvador, BA, Brazil

\begin{abstract}
Avascular necrosis (AVN) of the femoral head is an emerging complication in HIV infected patients. It has been suggested that the increased incidence of AVN in this population may be caused by an increased prevalence of predisposing factors for osteonecrosis, including protease inhibitors, hyperlipidemia, corticosteroid use, alcohol and intravenous drug abuse. The aim of this study was to assess the risk factors for avascular necrosis developing in the femoral head of HIV infected individuals. This study consisted of meta-analysis of the secondary data extracted from current literature. The selected articles allowed two study groups to be drawn up for comparison. Group 1 comprised 324 individuals infected by the HIV virus, who did not present femoral head AVN. Group 2 comprised 32 HIV positive patients, who presented femoral head AVN. The parameters used for analysis were as follows: age, gender, sexual preference, use of intravenous drugs, time of diagnosis, $\mathrm{CD}^{+}$cell count, use of antiretroviral agents and duration, serum cholesterol and serum triglycerides. The present study found a statistically significant association between hypertriglyceridemia, hypercholesterolemia, sexual preference and intravenous drug abuse. The authors concluded that femoral head osteonecrosis is associated with hyperlipidemia (hypercholesterolemia and hypertriglyceridemia) and intravenous drug abuse. This study supports the hypothesis that protease inhibitors play a role in the development of osteonecrosis through a tendency to cause hyperlipidemia.
\end{abstract}

Key Words: AIDS, HIV, avascular necrosis.

Avascular necrosis (AVN) of the femoral head is an emerging complication in HIV infected patients. It has been reported that the incidence of AVN in HIV patients is $0.45 \%$, which is 45 times greater than in the normal population [1,2].

In recent reports AVN has been associated with the use of protease inhibitor-containing (PI) regimens, since antiretroviral therapy may cause hyperlipidemia and osteoporosis [1,3]. On the other hand, in some patients, AVN may develop before PI therapy begins [1]. It has been suggested that the HIV condition itself, or some other factors, such as hypercholesterolemia, hypertriglyceridemia, corticosteroid use and alcohol abuse may increase the risk of AVN development in these patients [1,2].

The aim of this study was to assess, by means of metaanalytic review, the risk factors for avascular necrosis developing in the femoral head of HIV infected individuals.

\section{Materials and Methods}

The work consisted of metaanalysis of the secondary data extracted from current literature about the subject. A review was made of the Latin American and Caribbean Health Science Literature (Literatura Latinoamericana e do Caribe em Ciências da Saúde - LILACS) and Medline for the period from 1995 to 2005, using the following descriptors: "AIDS", "HIV”, "osteonecrosis", "avascular”, "femoral head", "protease inhibitors".

The studies were classified in accordance with their importance to the subject and with the methodology used. Six case reports[2-7] and one case control study [8] were

Received on 4 September 2006; revised 29 December 2006.

Address for correspondence: Dr. Marcos Almeida Matos. Rua da Ilha, 378, casa 21, Itapuã, Salvador-Bahia, Brazil. Zip code: 41620-620.

The Brazilian Journal of Infectious Diseases 2007;11(1):31-34. (C) 2007 by The Brazilian Journal of Infectious Diseases and Contexto Publishing. All rights reserved. accepted. No prospective studies were found. Articles that related cases of HIV positive patients, with complete (or partially complete) history containing data about the risk factors to be assessed and that referred to the presence or absence of AVN were included. Articles that did not fit in with these criteria or that did not provide sufficient data for statistical analysis were excluded.

The selected articles allowed two study groups to be drawn up for comparison. Group 1, denominated "control” comprised 324 individuals infected by the HIV virus, who did not present with femoral head AVN [8]. Group 2, denominated "study", comprised 32 HIV positive patients, who presented with femoral head AVN, obtained out of seven reports of one or more cases [2-8].

The data obtained from the articles were re-tabulated for descriptive presentation. The parameters used for analysis were as follows: age, gender, sexual preference, use of intravenous drugs, time of diagnosis, $\mathrm{CD} 4^{+}$cell count, use of antiretroviral agents and duration, serum cholesterol and serum triglycerides.

Association with categorical data was evaluated by using chi-square test; continuous variables were evaluated by using student t-test. We considered " $p$ " values less than 0.05 to be statistically significant.

\section{Results}

The control group (Group 1) in the present study comprised 324 individuals infected by the HIV virus, who did not present with femoral head avascular necrosis [8]. This group was clinically assessed by laboratory exams and by magnetic resonance of the hips [8]. All the patients in this study had dosage of $\mathrm{CD} 4^{+}$, serum cholesterol and triglycerides. In all the cases there was report of age, gender, sexual behavior, use of intravenous drugs, time of infection diagnosis, use and time of treatment with antiretroviral drugs, alcohol abuse and use of steroids [8]. 
The group of HIV positive patients that presented femoral head avascular necrosis (Group 2) was obtained from seven report studies and one or more cases published in journals indexed on MEDLINE [2-8].

Group 2 comprised 32 patients. All the studies related the gender, age, $\mathrm{CD} 4^{+}$count, use of antiretroviral drugs with duration of treatment of all the patients. Five studies related the sexual behavior $[2,4,5,7,8]$, adding up to 29 patients; use of intravenous drugs was related in five studies (29 cases) $[2,4,5,6,8]$; time of infection diagnosis was mentioned in six studies, totaling 31 cases [2-6,8]; total cholesterol was dosed in 25 cases (four studies) [3,4,6,8]; triglycerides were obtained in 31 cases (six studies) [3-8]; alcohol abuse was related in five studies (24 cases) $[2,3,5,7,8]$; steroid use was related in five studies, totaling 24 cases $[2,3,5,7,8]$.

The comparative results have been distributed in Tables 1 to 11 .

Table 1. Data of corticosteroid use

\begin{tabular}{lccc}
\hline Groups & Yes (\%) & No (\%) & Total \\
\hline Group 1 & $143(44.1)$ & $181(55.9)$ & 324 \\
Group 2 & $12(50)$ & $12(50)$ & 24 \\
Total & 155 & 193 & 348 \\
\hline P $=0.5$ (odds
\end{tabular}

Table 2. Data of alcohol abuse

\begin{tabular}{lccc}
\hline Groups & Yes (\%) & No (\%) & Total \\
\hline Group 1 & $32(9.8)$ & $292(90.2)$ & 324 \\
Group 2 & $3(12.5)$ & $18(87.5)$ & 32 \\
Total & 35 & 313 & 348 \\
\hline
\end{tabular}

$\mathrm{P}=0.952$ (odds ratio $=1.13$ ).

Table 3. Data of antiretroviral therapy use

\begin{tabular}{lccc}
\hline Groups & Yes (\%) & No (\%) & Total \\
\hline Group 1 & $298(91.9)$ & $26(8.1)$ & 324 \\
Group 2 & $28(87.5)$ & $4(12.5)$ & 32 \\
Total & 326 & 30 & 356 \\
\hline P $=0.592$ (odds ratio $=0.62)$ & &
\end{tabular}

Table 4. Data of intravenous drug abuse

\begin{tabular}{lccc}
\hline Groups & Yes (\%) & No (\%) & Total \\
\hline Group 1 & $6(1.8)$ & $318(98.2)$ & 324 \\
Group 2 & $7(24.1)$ & $22(75.9)$ & 29 \\
Total & 13 & 340 & 353 \\
\hline
\end{tabular}

$\mathrm{P}<0.05$ (odds ratio $=16,87$ ).
Table 5. Data of sexual preference (homosexualism)

\begin{tabular}{lccc}
\hline Groups & Yes (\%) & No (\%) & Total \\
\hline Group 1 & $279(86.2)$ & $45(13.8)$ & 324 \\
Group 2 & $20(69)$ & $9(31)$ & 29 \\
Total & 299 & 54 & 353 \\
\hline
\end{tabular}

$\mathrm{P}=0.029$ (odds ratio $=2.79$ ).

Table 6. Data of gender

\begin{tabular}{lccc}
\hline Groups & Male (\%) & Female (\%) & Total \\
\hline Group 1 & $297(91.7)$ & $27(8.3)$ & 324 \\
Group 2 & $28(87.5)$ & $4(12.5)$ & 32 \\
Total & 325 & 31 & 356 \\
\hline
\end{tabular}

$\mathrm{P}=0.639$ (odds ratio $=0.64$ ).

Table 7. Data of antiretroviral therapy duration (months)

\begin{tabular}{lc}
\hline Groups & Mean (standard desviation) \\
\hline Group 1 & $28.6(14.1)$ \\
Group 2 & $25.91(21.75)$ \\
\hline $\mathrm{P}=0.331$. &
\end{tabular}

Table 8. Data of serum cholesterol

\begin{tabular}{lc}
\hline Groups & Mean (standard desviation) \\
\hline Group 1 & $252(82)$ \\
Group 2 & $181.82(67.34)$ \\
\hline $\mathrm{P}<0.05$ &
\end{tabular}

$\mathrm{P}<0.05$.

Table 9. Data of time of diagnosis

\begin{tabular}{lc}
\hline Groups & Mean (standard desviation) \\
\hline Group 1 & $104(48)$ \\
Group 2 & $104.4(44.9)$ \\
\hline $\mathrm{P}=0.964$. &
\end{tabular}

Table 10. Data of serum triglycerides

\begin{tabular}{lc}
\hline Groups & Mean (standard desviation) \\
\hline Group 1 & $576(566)$ \\
Group 2 & $290.41(273.73)$ \\
\hline
\end{tabular}

$\mathrm{P}=0.006$.

Table 11. Data of CD4+ cells count

\begin{tabular}{lc}
\hline Groups & Mean (standard desviation) \\
\hline Group 1 & $281(164)$ \\
Group 2 & $276.55(295.32)$ \\
\hline
\end{tabular}

$\mathrm{P}=0.894$. 


\section{Discussion}

Case reports of femoral head osteonecrosis in persons with HIV infection have appeared in the literature since 1990 $[1,9]$. It has been suggested that the apparent increased incidence of AVN in this population may be caused by an increased prevalence of predisposing factors for osteonecrosis, including hyperlipidemia, corticosteroid use and alcohol abuse [1,9].

A variety of etiologic associations with osteonecrosis has been proposed and has been more or less convincingly demonstrated. They include corticosteroid intake and excessive alcohol use. Avascular necrosis occurs in 8 to $10 \%$ of patients exposed to corticosteroid therapy [10]. With some diseases, it is difficult to separate the effects of corticosteroids on bone from those of the underlying diseases. Excessive alcohol intake has been identified as an etiologic factor, but it is difficult to define the term "excessive" [10].

No association was found between alcohol abuse or corticosteroid use, but the accuracy of determining the role of these risk factors may be limited in the present metaanalysis study. Details of a patient's alcohol use and prior steroid treatment would be better determined by direct interview with the patient.

Following the introduction of HAART (highly active antiretroviral therapy), and in particular protease inhibitor therapy, the number of cases of AVN has increased, with 21 cases being published between 1998 and 1999 [7].

Protease inhibitor therapy may have effects on bone metabolism. Some authors have found that protease inhibitors can induce osteoporosis[1], whereas others suppose that these drugs can improve bone remodeling, since an effective PI therapy can normalize the level of proinflamatory cytokines involved in the bone remodeling process [11].

It is unlikely that protease inhibitor therapy is the only explanation for a possible increased risk factor for AVN, because case reports first began to appear in the literature before these agents became available [1]. It was hypothesized that these drugs could lead to osteonecrosis because of their metabolic complications, such as hyperlipidemia, a syndrome of peripheral lipodystrophy and osteoporosis [1].

In the present study no association was found between osteonecrosis and use or duration of protease inhibitor therapy, but its results cannot be extrapolated to patients who are not receiving PI therapy, because these drugs were used in more than $90 \%$ of the cases. On the other hand the present study found a strong association between hypertriglyceridemia and hypercholesterolemia. It supports the hypothesis that protease inhibitors play an important role in the development of osteonecrosis through a tendency to cause hyperlipidemia [1,3,12].

Most of the patients appear to have no known predisposing factor for AVN and it has been suggested that HIV infection itself may be a risk factor for osteonecrosis [1]. HIV could act by directly facilitating cytokine mediated bone reabsorption [7]. In fact, bone tissue homeostasis is regulated by proinflamatory cytokines, in particular IL-6 and TNF, which are also involved in HIV pathogenesis [7].

Osteonecrosis may occur in patients with subclinical coagulopathies [13] and persons with HIV frequently have elevated levels of antiphospholipid antibodies [14]. Belmonte in 1993 [15] described a possible association between the presence of antiphospholipid antibodies and osteonecrosis in patients with HIV disease. It is suggested that immunologic disturbance occurring early in the course of HIV infection may predispose the patient to avascular necrosis [16].

The presence of antiphospholipid antibodies is associated with both arterial and venous thrombosis, as well as thrombocytopenia [15], which suggests that increased intraosseous platelet aggregation and fibrin platelet thrombosis may produce intravascular coagulation, ischemia, and bone necrosis.

The authors were unable to find a correlation between $\mathrm{CD}^{+}$and femoral head osteonecrosis, but the patients in the present study were not evaluated for antiphospholipid antibodies, because most of the case reports lack complete data, such as antiphospholipid antibodies levels. Moreover, the present study is unable to support the idea that HIV itself may be a risk factor for bone necrosis.

Finally, the present study found association between intravenous drug abuse and sexuality with osteonecrosis. Heterosexuals had an odds ratio of 2.79 and intravenous drug users had an odds ratio of 16.87. Intravenous drug abuse is commonly associated with deep vein thrombosis and it may lead to bone necrosis and infection [17]. Antiphospholipid antibodies were detected in about 60\% of HIV positive intravenous drug addict patients and it is possible that the drug itself may be responsible for osteonecrosis [18]. This group of individuals, in turn, may acquire HIV infection by the intravenous path and not necessarily because of their sexual practices, justifying the high prevalence of heterosexualism in this group.

\section{Conclusion}

The authors concluded that femoral head osteonecrosis is associated with hyperlipidemia (hypercholesterolemia and hypertriglyceridemia) and intravenous drug abuse. This study supports the hypothesis that protease inhibitors play a role in the development of osteonecrosis through a tendency to cause hyperlipidemia. Because of the limitations of the present study, the authors are unable to assess the role of HIV itself as a risk factor for bone necrosis. It is likely that the etiology of avascular necrosis in patients with HIV is multifactorial and further study of the role of risk factors is needed.

\section{References}

1. Brown P., Crane L. Avascular necrosis of bone in patients with hguman immunodeficiency virus infection: report of 6 cases and review of the literature. AIDS 2001;32:1221-6.

2. Cagatay A.A., Diz-Kucukkaya R., Akyildiz GM., et al. Human immunodeficiency virus and avascular necrosis of the femoral head: a case report. Chin Med J 2004;117:1437-40. 
3. Meyer D., Behrens G., Schimidt R.E., Stoll M. Osteonecrosis of the femoral head in patients receiving HIV protease inhibitors. 1999; $13: 1147-9$.

4. Calza L., Manfredi R., Chiodo F. Oetéonécrose chez les patients infectés par le VIH et ses relations avec la thérapie antirétrovirale hautement active (HAART). Presse Med 2003;32:595-8.

5. Valencia M.E., Moreno V., Soriano V., Blanco F., González-Lahoz J. Necrosis avascular de la cabeza femoral em pacientes com infección por el virus de la inmunodeficiencia humana em tratamiento antirretrovírico. Enferm Infecc Microbiol Clin 2001;19:503-5.

6. Bongiovanni M., Chiesa E., Riva A., Mongfgorte A.D., Bgingi T. Avascular necrosis of the femoral head in a HIV-1 infected patient receiving lopinavir/ritonavir. Intern J Antimicrobial Agents 2003;22:630-1.

7. Sighinolfi L., Carradori S., Ghinelli F. Avascular Necrosis of the Femoral Head: A Side Effect of Highly Active Antiretroviral Therapy (HAART) in HIV Patients? Infection 2000;28:254-5.

8. Miller K.D., Masur H., Jones E.C., et al. High Prevalence of Osteonecrosis of the Femoral Head in HIV-Infected Adults. Ann Intern Med 2002; 137:17-25.

9. Scribner A.N., Troia-Cancio P.V., Cox B.A., et al. Osteonecrosis in HIV: a case-control study. J Acquir Immune Defic Syndr 2000;25:19-25.

10. Lieberman J.R., Berry D.J., Mont M.A., et al. Osteonecrosis of the hip: management in the twenty-first century. $\mathrm{J}$ Bone Joint Surg 2002;84-A:834-56.
11. Aukrust P., Haug C.J., Ueland T., et al. Decreased bone formative and enhaced resoptive markers in human immunodeficiency virus infection: indication of normalization of the boneremodeling process during highly active antiretroviral therapy. J Clin Endocrinol Metab 1999;84:145-50

12. Bonfanti P., Grabbuti A., Carradori S., et al. Osteonecrosis in protease inhibitor-treated patients. Orthopaedics 2001;24:271-2.

13. Gleuck C.J., Freiberg R., Tracy T., Stroop D., Wang P. Thrombophilia and hypofibrinolysis: pathophysiologies of osteonecrosis. Clin Orthop 1997;43-56.

14. Reis M.D., Barcohana B., Davidson A., Jergesen H.E., Paiement D. Association between human immunodeficiency virus and osteonecrosis of the femoral head. J Arthroplasty 2002; 17:135-9.

15. Belmonte M.A., García-Portales, Doménech I., et al. Avascular necrosis of bone in human immunodeficiency virus infection an antiphospholipid antibodies. J Rheumatol 1993;20:1425-8.

16. Rademaker J., Dobro J.S., Solomon C.G. Osteonecrosis and human immunodeficiency virus infection. J Rheumatol 1997;24:601-4.

17. Liu H.S., Kho B.C., Chan J.C., et al. Venous thromboembolism in the chinise population - experience in a regional hospital in Hong Kong. Hong Kong Med J 2002;8:400-5.

18. Muniz-Diaz E., Doming P., Lopez M., et al. Thrombocytopenia associated with human immunodeficiency vírus infection. Immunologic study of 60 patients addicted to parenteral drugs. Med Clin (Barc) 1995;28:118-9. 